\title{
Implicações técnicas e ecossistêmicas do manejo inadequado da arborização urbana: o caso das podas drásticas em oitis na cidade de Ilha Solteira - SP
}

\author{
Patrick L.F. Santos ${ }^{a}$, Caroline M.D. Mateus ${ }^{a}$, Regina M. Castilhob ${ }^{b}$ Maximiliano K. Pagliarinic, Alessandro R. Zabotto ${ }^{a}$, Mauricio L. Ferreirad"* \\ ${ }^{a}$ Universidade Estadual Paulista (UNESP), Faculdade de Ciências Agronômicas, Botucatu-SP, Brasil. \\ ${ }^{\mathrm{b}}$ Universidade Estadual Paulista (UNESP), Faculdade de Engenharia de Ilha Solteira, Ilha Solteira-SP, Brasil. \\ ${ }^{\mathrm{C}}$ Universidade Federal da Grande Dourados (UFGD), Fazenda Experimental de Ciências Agrárias, Dourados-MS, Brasil. \\ ${ }^{\mathrm{d} C e n t r o ~ U n i v e r s i t a ́ r i o ~ A d v e n t i s t a ~ d e ~ S a ̃ o ~ P a u l o ~(U N A S P), ~ P r o g r a m a ~ d e ~ M e s t r a d o ~ e m ~ P r o m o c ̧ a ̃ o ~ d a ~ S a u ́ d e, ~ S a ̃ o ~ P a u l o-S P, ~ B r a s i l . ~}$
}

Informações

Recebido 05 Outubro 2019

Manuscrito revisado recebido

14 Dezembro 2019

Aceito 19 Dezembro 2019

Palavras-chave

Licania tomentosa

Manejo arbóreo

Arborização de vias públicas

Crime ambiental

\section{Resumo}

O Oiti é uma espécie de grande porte, recomendada para arborização urbana. Contudo, muitas vezes é implantada em locais inadequados, o que pode ocasionar conflitos com alguns fatores nas cidades e com a população em geral. Assim, podas inadequadas são realizadas, ocasionando grandes prejuízos na planta e para a gestão pública. O objetivo deste trabalho foi analisar as podas drásticas realizadas em árvores de Oiti utilizadas na arborização urbana no município de Ilha Solteira - SP. Foram diagnosticados exemplares de Oiti consideradas com poda drástica e coletados dados referentes à localização, presença de fiação e pedido de poda junto a Prefeitura Municipal. Foram elencados os motivos para a realização da poda, o registro das árvores por fotos digitais, que foram comparadas com imagens do Google Street View ${ }^{\circledR}$ anteriores à realização da poda. Concluiu-se que árvores de Oiti receberam poda drástica em diversos bairros da cidade de Ilha Solteira, sendo estas realizadas sem justificativa e solicitação/anuência da Prefeitura Municipal, resultando em alguns casos na morte da árvore e consequente perda do verde urbano.

\section{Technical and ecosystem implications of inadequate management of urban afforestation: the case of drastic pruning in oitis in the city of Ilha Solteira - SP}

\section{Article info}

Received 05 October 2019

Received in revised form 14 December 2019

Accepted 19 December 2019

\section{Keywords}

Licania tomentosa

Management of trees

Afforestation of public

spaces

Enviromnetal crime

\begin{abstract}
Oiti is a large species, recommended for urban afforestation. However, it is often implemented in inappropriate places, which can cause conflicts with some factors in cities and with the population in general. Thus, inadequate pruning is carried out, causing great damage to the plant and to public management. The objective of this work was to analyze the drastic pruning performed on Oiti trees used in urban afforestation in the municipality of IIha Solteira - SP. Oiti specimens diagnosed with drastic pruning were diagnosed and data related to location, presence of electriclal cables and pruning order were collected from the City Hall. The reasons for pruning were listed, the trees were registered using digital photos, which were compared to images from Google Street View ${ }^{\circledR}$ prior to the pruning. It was concluded that Oiti trees received drastic pruning in several neighborhoods in the city of Ilha Solteira, which were carried out with no justification nor request/consent from the City Hall, resulting in some cases in the death of the tree and consequent loss of urban green.
\end{abstract}

\section{Implicaciones técnicas y ecosistémicas de la gestión inadecuada de la forestación urbana: el caso de la poda drástica en oitis en la ciudad de llha Solteira - SP}

\section{Información}

Recibido 05 Octubre 2019

Manuscrito revisado recibido 14 Diciembre 2019

Aceptado 19 Diciembre 2019

\section{Palabras clave}

Licania tomentosa

Manejo de árboles

Forestación de vias públicas Delito ambiental

\section{Resumen}

Oiti es una especie grande, recomendada para forestación urbana. Sin embargo, muchas veces se implementa en lugares inadecuados, lo que puede generar conflictos con algunos factores en las ciudades y con la población en general. Así, se realiza una poda inadecuada, provocando grandes daños a la planta y a la gestión pública. El objetivo de este trabajo fue analizar la poda drástica realizada en árboles de Oiti utilizados en forestación urbana en el municipio de Ilha Solteira - SP. Ejemplares de Oiti diagnosticados con poda drástica fueron diagnosticados y los datos relacionados con la ubicación, presencia de cables y orden de poda se recogieron del Ayuntamiento. Se enumeraron los motivos de la poda, los árboles se registraron mediante fotografías digitales, que fueron comparadas con imágenes obtenidas de Google Street View ${ }^{\circledR}$ antes de la poda. Se concluyó que los árboles de Oiti recibieron podas drásticas en varios barrios de la ciudad de Ilha Solteira, que se llevaron a cabo sin justificación ni solicitud/consentimiento del Ayuntamiento, resultando en algunos casos en la muerte del árbol y la consiguiente pérdida de verde urbano.

\footnotetext{
* Autor correspondente em: Centro Universitário Adventista de São Paulo (UNASP), Programa de Mestrado em Promoção da Saúde. 


\section{Introdução}

A arborização de vias públicas desempenha papel fundamental na qualidade ambiental em áreas urbanas. A presença de vegetação nas cidades proporciona melhorias de ordem social e microclimática, minimiza a poluição do ar, visual e sonora, além de propiciar condições para a manutenção da flora e fauna (MASCARÓ; MASCARÓ, 2002; SANTOS; CASTILHO, 2018).

Embora as cidades brasileiras estejam predominantemente sob uma condição climática favorável para o desenvolvimento vegetal, o ambiente construído apresenta particularidades que muitas vezes dificulta a permanência da elevada biodiversidade que naturalmente ocorre nos biomas do país, levando muitas vezes a um quadro de homogeneização biótica (MENDONÇA; FERREIRA, 2019).

Uma espécie bastante comum em cidades do Sudeste do Brasil é a Licania tomentosa (Benth.) Fritsch., da família Chrysobalanaceae, popularmente conhecida como Oiti. Esta árvore é perenifólia, nativa da Floresta Pluvial Atlântica, e ocorre desde Pernambuco até o norte do Espírito Santo e vale do Rio Doce em Minas Gerais. Em termos biométricos, a sua altura pode variar de 6 a $15 \mathrm{~m}$, sendo considerada uma árvore de grande porte, com tronco de 30 a $50 \mathrm{~cm}$ de diâmetro. Encontra-se nesta espécie folhas simples, tomentosas em ambas as faces, de 7 a $14 \mathrm{~cm}$ de comprimento e 3 a $5 \mathrm{~cm}$ de largura. O florescimento do Oiti ocorre durante os meses de junho-agosto e seus frutos amadurecem em janeiro-março (LORENZI, 2008). Quando não são impostas restrições ao seu crescimento em altura por meio de podas, L. tomentosa apresenta copa frondosa que proporciona sombra, característica bastante atrativa que justifica seu uso em larga escala na arborização urbana por quase todo o Brasil (FERREIRA; GASPAROTTO; LIMA, 2001).

Contudo, o histórico de urbanização mostra que a arborização das cidades brasileiras, em sua maioria, não obedece a um planejamento, tendo como consequência diversos problemas como a escolha inadequada da espécie e o plantio em locais inapropriados, trazendo assim conflitos e gerando prejuízos para a gestão pública das cidades (PERIOTTO et al, 2019). Neste sentido, cabe destacar o exemplo de perda financeira relacionada a arborização urbana ocorrida em uma cidade média no estado da Flórida, EUA, a qual gastou aproximadamente US\$ 240 mil por ano em reparos com a poda das árvores de ruas, sendo que este gasto representou na época a terceira atividade de manutenção mais cara na cidade (ESCOBEDO; SEITZ, 2012).

Para que as árvores cumpram suas funções no ambiente urbano, mantendo-se em estado adequado e sadio, é necessária a adoção de práticas sistematizadas de manutenção, dentre as quais a poda, que deve ser conduzida por profissionais e norteada por conhecimentos técnico-científicos (MILANO; DALCIN, 2000).

Todavia, a poda das árvores é regulamentada por leis municipais e, para que seja realizada adequadamente, é necessário realizar um pedido junto à Prefeitura da cidade. Assim, após a aprovação, a poda deve ser realizada seguindo normas técnicas, de forma a não prejudicar o desenvolvimento do vegetal. Em IIha Solteira - SP, a Lei Ordinária Municipal 441, de 11 de abril de 1997, que "Disciplina o plantio de árvores no município de Ilha Solteira e dá outras providências", estabelece no artigo 16 as condições para permissão de supressão e podas (ILHA SOLTEIRA, 1997).

Entretanto, quando a poda é conduzida inadvertidamente, sem o uso de técnicas específicas, prejudica o crescimento da árvore, deixando-a exposta a agentes externos e ainda desconfigurando sua arquitetura. A exposição do lenho permite a entrada de microrganismos e artrópodes que degradam a madeira e afetam negativamente sua fitossanidade. Os aspectos fitossanitários negativos mais notados em árvores urbanas são os ataques por pragas e doenças, responsáveis pela biodeterioração do vegetal (MARTINS; ANDRADE; ANGELIS, 2010).

Este conjunto de funções acarreta na perda de serviços ecossistêmicos oferecidos pela arborização urbana, tais como sequestro e estoque de carbono, amenização climática e atenuação de níveis de poluição atmosférica (MENDONÇA; FERREIRA, 
2019).

Tendo em vista as responsabilidades de tal manejo, o agente que conduzir inadequadamente o serviço, ou seja, praticando a poda drástica pode ser autuado, visto que a prática é considerada crime ambiental, conforme a Lei Federal 9.605/98, Art. 49: "Destruir, danificar, lesar ou maltratar, por qualquer modo ou meio, plantas de ornamentação de logradouros públicos ou em propriedade privada alheia", tendo como "Pena a detenção de três meses a um ano, ou multa, ou ambas as penas cumulativamente" (BRASIL, 1998).

Neste sentido, cabe destacar que Marek (2008) conceitua claramente a poda drástica como aquela que apresenta i) remoção total da copa, permanecendo acima do tronco apenas os ramos principais com menos de um metro de comprimento nas árvores adultas; ii) remoção total de um ou mais ramos principais, resultando no desequilíbrio da árvore, ou ainda iii) remoção total da copa da árvore, restando apenas o tronco.

Identificar e discutir as implicações técnicas e ecossistêmicas de podas drásticas à luz da literatura científica pode auxiliar a gestão pública na gestão da arborização urbana, de modo que este componente da paisagem das cidades se torne cada vez mais eficiente no aspecto cênico, ecológico e funcional dos centros urbanos. Diante do exposto, o trabalho teve como objetivo analisar as podas drásticas realizadas em árvores de Oiti na arborização urbana no município de Ilha Solteira SP.

Embora cada cidade brasileira apresente características peculiares da arborização urbana, os resultados deste estudo poderão ser extrapolados para outros contextos urbanos, envolvendo inclusive outras espécies arbóreas.

\section{Materiais e métodos}

\section{1. Área de estudo}

O trabalho foi conduzido no ano de 2018 na cidade de Ilha Solteira - SP (Figura 1), latitude $20^{\circ} 22^{\prime}$ S, longitude $51^{\circ} 22$ 'WGR, altitude média

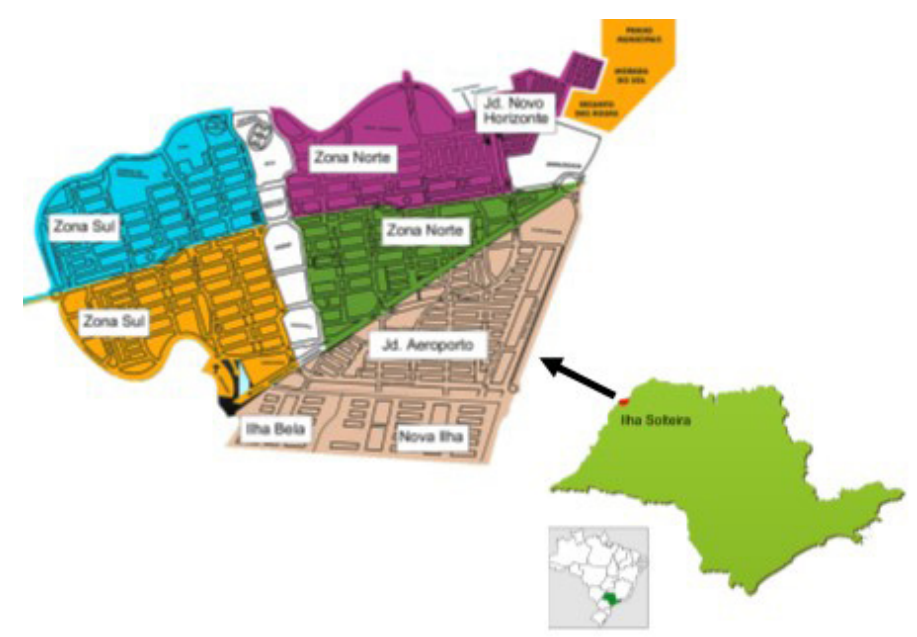

Fig. 1. Localização da cidade de Ilha Solteira - SP, latitude $20^{\circ} 22$ 'S, longitude $51^{\circ} 22$ 'WGR (REDE CIDADE DIGITAL, 2018) com detalhe do mapa da cidade e divisão dos bairros (ILHA SOLTEIRA, 2018 adaptado).

de $335 \mathrm{~m}$ com população de 26.443 habitantes (IBGE-2017). Segundo a classificação de Köppen, o clima da região é do tipo Aw, caracterizado por estação chuvosa no verão e seca no inverno, definido como tropical úmido, apresentando no ano do estudo temperatura média anual de $25,3^{\circ} \mathrm{C}$, com temperaturas médias máximas e mínimas de $32,4^{\circ} \mathrm{C}$ e $19,7^{\circ} \mathrm{C}$, respectivamente, e precipitação anual de 1.143,9 mm com umidade relativa média anual de 74\% (DADOS CLIMÁTICOS, 2018).

\subsection{Coleta de dados arbóreos}

No início do trabalho, sete árvores de Oiti foram identificadas e analisadas visualmente quanto a poda drástica em diferentes partes da cidade, com posterior coleta da imagem dos indivíduos. A partir deste levantamento, utilizou-se uma ficha de campo em que os critérios de análise foram adaptados de Silvanow (2002) e Bortoleto (2004), entre eles: Identificação, número de controle atribuído a cada árvore, logradouro, presença de fiação e coordenadas geográficas.

Após a coleta de dados, os moradores das residências próximas aos indivíduos de Oitis foram entrevistados, a fim de justificar a realização da poda e confrontar junto a Prefeitura da cidade se houve o pedido de poda, como estabelecido pela lei ordinária municipal 441, de 11 de abril de 1997 (ILHA SOLTEIRA, 1997). 
Ainda, foram identificadas imagens pelo Google Street View ${ }^{\circledR}$ de anos anteriores a 2017, dos mesmos locais onde foram coletados os dados das árvores, para comparação de cada exemplar antes e depois da poda.

\section{Resultados e discussão}

A cidade de Ilha Solteira apresenta algumas particularidades quanto a arborização urbana, porém, para fins deste artigo, limitou-se aos registros dos Oitis nas vias públicas.

Nota-se que, dentre os exemplares de Oiti diagnosticados com poda drástica, nenhum estava sob conflito com fiação (Quadro 1) ou outros equipamentos da via. Outro ponto interessante é que dentre os casos analisados, observouse que para realização da poda, em nenhum dos casos avaliados houve solicitação junto à Prefeitura Municipal, conforme estabelecido pela Lei Municipal de IIha Solteira - SP. Dentre os sete casos observados, destaca-se que as justificativas apresentadas pelos munícipes para realização das podas se restringiram a duas condições, a saber: i) eles argumentaram que as árvores foram podadas devido ao fator "entupimento de calha", enquanto outros munícipes alegaram que foi devido a "alergia ao pó da folha da árvore".

O Quadro 1 apresenta os resultados das árvores constatadas com poda drástica na cidade de Ilha Solteira - SP. A justificativa dada pelos moradores sobre o entupimento das calhas faz muito sentido quando as espécies presentes na arborização urbana apresentam elevada taxa de deciduidade, ou seja, há uma grande perda de folhas ao longo do ano ou em uma determinada estação. Embora a espécie podada drasticamente, Licania tomentosa (Benth.) Fritsch., tenha folhas perenes típicas da Floresta Pluvial Atlântica, a qual é e adaptada a condição de alta umidade (LORENZI, 2008), notase que o comportamento decíduo da espécie seja diferenciado na região de IIha Solteira - SP. Pelo fato da cidade ser caracterizada como bioma de cerrado e devido ao tempo seco e sol intenso, as folhas da espécie acabam tendo ciclo mais curto, entrando em senescência mais rápido, apresentando assim queda com maior frequência.

Deste modo, pela espécie estar instalada em clima não propicio para suas condições fisiológicas, ocorre a perda das folhas com maior frequência, o que aumenta a possibilidade de serem depositadas em calhas. Diante deste fato, é de se esperar que haja conflito com os moradores, que acabam realizando a poda drástica como solução, sem procurar recursos alternativos. De acordo com a Prefeitura Municipal de São Paulo (2015), existem soluções inteligentes para resolver este tipo de problema, como por exemplo, a aplicação de telas filtro ou uso de ralos convexos nas calhas (Figura 2).

A outra justificativa pela poda drástica apontada pelos moradores foi "alergia ao pó da folha", na qual

Quadro 1. Oitis identificados com poda drástica na cidade de Ilha Solteira - SP.

\begin{tabular}{|c|c|c|c|c|c|}
\hline $\begin{array}{l}\text { Número do } \\
\text { caso }\end{array}$ & $\begin{array}{l}\text { Localização } \\
\text { (Bairro) }\end{array}$ & Sob fiação & $\begin{array}{c}\text { Solicitação de poda } \\
\text { à Prefeitura }\end{array}$ & $\begin{array}{l}\text { Justificativa do morador para } \\
\text { realização da poda }\end{array}$ & Coordenadas \\
\hline 01 & Zona Sul & Não & Não & Entupimento de calha & $\begin{array}{l}20^{\circ} 25^{\prime} 37.8^{\prime \prime} \mathrm{S} \\
51^{\circ} 20^{\prime} 48.5^{\prime \prime} \mathrm{W}\end{array}$ \\
\hline 02 & Zona Sul & Não & Não & Entupimento de calha & $\begin{array}{l}20^{\circ} 25^{\prime} 37.8^{\prime \prime} \mathrm{S} \\
51^{\circ} 20^{\prime} 48.5^{\prime \prime} \mathrm{W}\end{array}$ \\
\hline $\mathrm{O} 3$ & Zona Sul & Não & Não & Entupimento de calha & $\begin{array}{l}20^{\circ} 25^{\prime} 37.8^{\prime \prime} \mathrm{S} \\
51^{\circ} 20^{\prime} 48.5^{\prime \prime} \mathrm{W}\end{array}$ \\
\hline 04 & Zona Sul & Não & Não & Não identificada & $\begin{array}{l}20^{\circ} 25^{\prime} 58.5^{\prime \prime} \mathrm{S} \\
51^{\circ} 20^{\prime} 38.1^{\prime \prime} \mathrm{W}\end{array}$ \\
\hline 05 & Zona Sul & Não & Não & Não identificada & $\begin{array}{l}20^{\circ} 26^{\prime} 06.7^{\prime \prime S} \\
51^{\circ} 20^{\prime} 37.0^{\prime \prime} \mathrm{W}\end{array}$ \\
\hline 06 & Jd. Aeroporto & Não & Não & Alergia ao pó da folha & $\begin{array}{l}20^{\circ} 25^{\prime} 52.6 " \mathrm{~S} \\
51^{\circ} 20^{\prime} 01.7 " \mathrm{~W}\end{array}$ \\
\hline 07 & Jd. Aeroporto & Não & Não & Alergia ao pó da folha & $\begin{array}{l}20^{\circ} 25^{\prime} 52.6^{\prime \prime S} \\
51^{\circ} 20^{\prime} 01.7^{\prime \prime} \mathrm{W}\end{array}$ \\
\hline
\end{tabular}



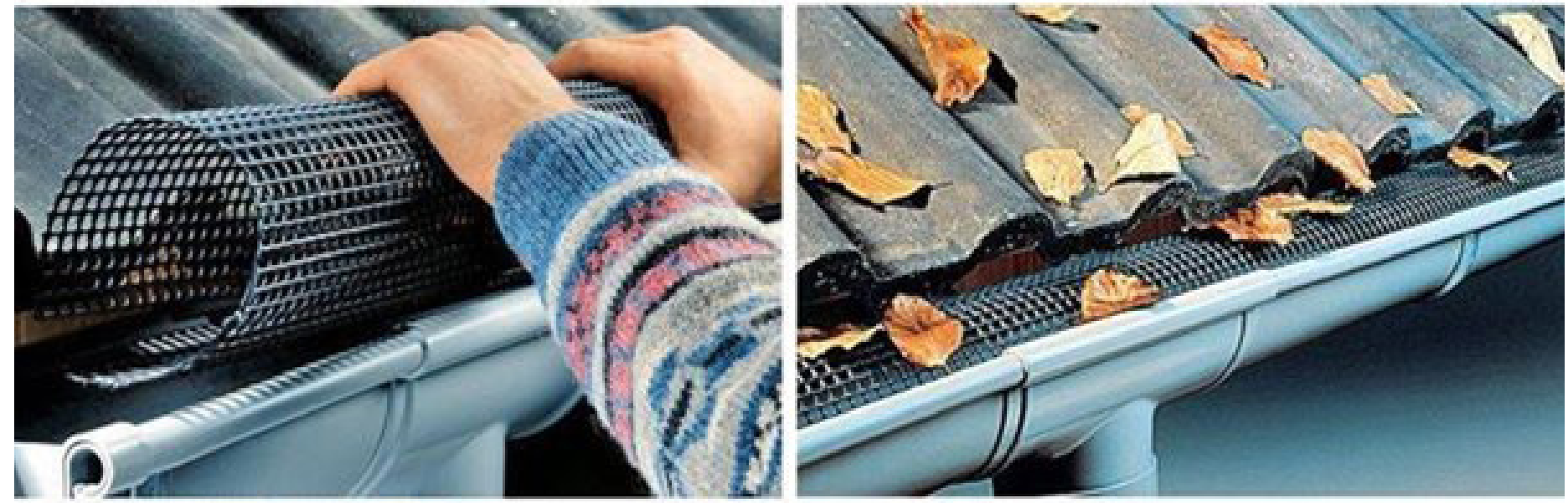

Fig. 2. Instalação de tela para evitar entumpimento da calha. Fonte: Pinterest (2019).

não existem relatos científicos de que a espécie Licania tomentosa ocasione tal reação. Destacase que é característica da espécie apresentar tomentos em suas folhas (LORENZI, 2008), sendo que, como outras árvores, contribuem na retenção da poluição do ar através da absorção de alguns poluentes e consequente atenuação de materiais particulados (BENNETT; HILL, 1975). Ainda assim, embora seja menos comum, existem árvores que causam reações alérgicas nas pessoas, como o caso do Cipreste-do-Arizona (Cupressus arizonica), Carvalho (Quercus spp.) que produz um pólen intenso (ABREU, 2018) e Aroeira Brava (Lithraea molleoides) que provoca a chamada "aroeirite" (GAUCHAZH, 2011).

As árvores de Oiti são predominantes na cidade de Ilha Solteira - SP, conforme relatado por Pinheiro et al. (2011), em trabalho com levantamento de espécimes arbóreas utilizadas na arborização urbana do município. Em seu estudo, ficou demonstrado que a espécie Licania tomentosa compõe 83\% das árvores do município, o que caracteriza uma hiperdominância. Em trabalhos de Possamai (2018), Costa e Higuchi (1999), Silva et al. (2002) e Silva Filho (2002) também foi demonstrado predomínio dessa espécie em outras cidades brasileiras, como em São Miguel do Iguaçu (PR), Manaus (AM), Uberlândia (MG) e Jaboticabal (SP), contribuindo com 61\%, 29\%, 32\% e 22\% da arborização total, respectivamente. Isso demonstra que a espécie é amplamente difundida e bem aceita na arborização urbana em várias regiões do País.
Devido ao porte do Oiti, ele deve ser plantado em locais propícios para seu desenvolvimento (BARROS; GUILHERME; CARVALHO, 2010). A Associação Brasileira de Normas Técnicas (ABNT, 2015), estabelece dimensões mínimas de largura da calçada para áreas urbanas dividindo em três faixas de uso: a) faixa de serviço $(0,70 \mathrm{~m})$ : serve para acomodar o mobiliário, os canteiros, as árvores e os postes de iluminação ou sinalização; b) faixa livre ou passeio: destina-se exclusivamente à circulação de pedestres, deve ser livre de qualquer obstáculo, ter inclinação transversal até 3\%, ser contínua entre lotes e ter no mínimo 1,20 m de largura e 2,10 m de altura livre; c) faixa de acesso: consiste no espaço de passagem da área pública para o lote. Esta faixa é possível apenas em calçadas com largura superior a 2,00 m. Tais características devem ser bem avaliadas antes do plantio da espécie escolhida, de forma que se evite futuros conflitos.

Visando a necessidade de escolher a espécie correta, para o local certo, a Prefeitura Municipal de São Paulo (SP) criou a chave arborizar, sendo este o primeiro item a ser avaliado, a largura da calçada. Essa chave, disponível gratuitamente no manual técnico de arborização urbana, auxilia o técnico responsável na decisão de plantar ou não uma árvore no local pretendido e, sendo viável o plantio, indica uma tabela de espécies para a escolha (PREFEITURA MUNICIPAL DE SÃO PAULO, 2015). Assim, árvores de grande porte somente devem ser plantadas em espaços amplos, como parques e praças, o que evita o conflito de sua copa com construções, fiação elétrica e também de suas raízes com a calçada e tubulações subterrâneas 
(CARCERERI et al., 2016; PERIOTTO et al, 2019).

Dessa forma, o Oiti por ser uma espécie de grande porte, não é recomendada para plantio em calçadas, como ocorre comumente no município de Ilha Solteira - SP. Mesmo que atualmente temse intensificado o uso de calçadas verdes, com a utilização de árvores em conjunto com forrações (como as gramas), para aumentar a área livre permeável (OLIVEIRA, et al., 2018), o Oiti não teria espaço suficiente para seu desenvolvimento pleno em fase adulta.

As Figuras 3a e 3b mostram as árvores 01, 02 e 03 em imagens do Google Street View ${ }^{\circledR}$ em ano anterior a poda drástica; as Figura 3c e 3d mostram as mesmas árvores após sofrer a poda drástica. A Figura 4 apresenta as árvores números 04, 05, 06 e 07 (Quadro 1) no ano anterior (4a, 4c, 4e) e após sofrer a poda drástica (4b, 4d, 4f) respectivamente.

Observa-se pelas imagens, que todas as árvores sofreram poda drástica, sendo retirada toda a sua copa. Inclusive, nas árvores identificadas na figura 3 (c, d), não ocorreu a rebrota, tendo a poda drástica causado a morte da planta. De acordo com Seitz (1996), após sofrer poda drástica, a exposição súbita a altas temperaturas geradas pela insolação direta, pode causar a morte das células da casca
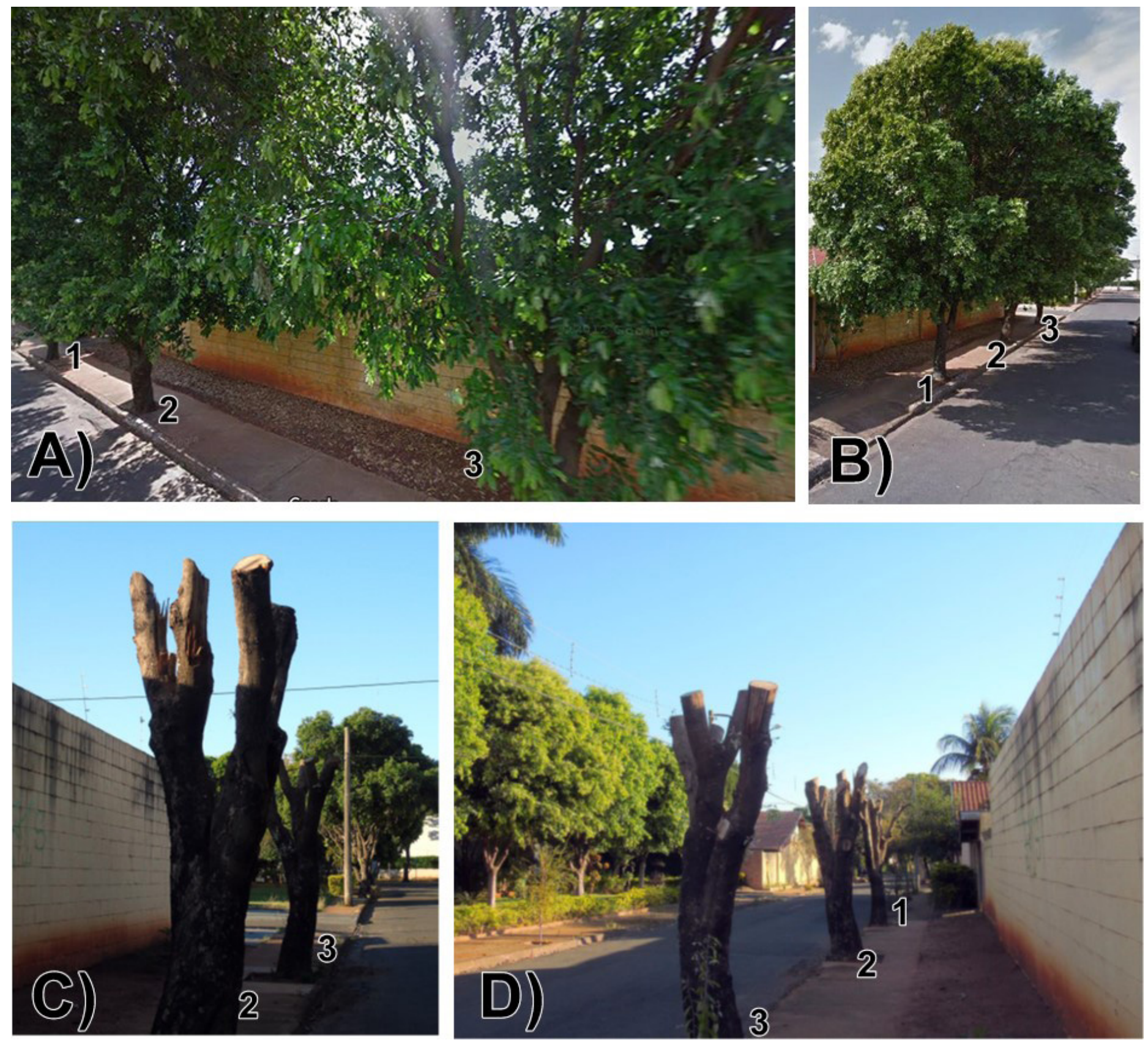

Fig. 3. Árvores de Oiti em Ilha Solteira - SP. (a, b) antes e (c, d) após sofrer poda drástica. Fonte: (a, b) Google Street View ${ }^{\oplus}$; (c, d) próprio autor. Localização: 20²5’37.8”S 51²0’48.5”W 

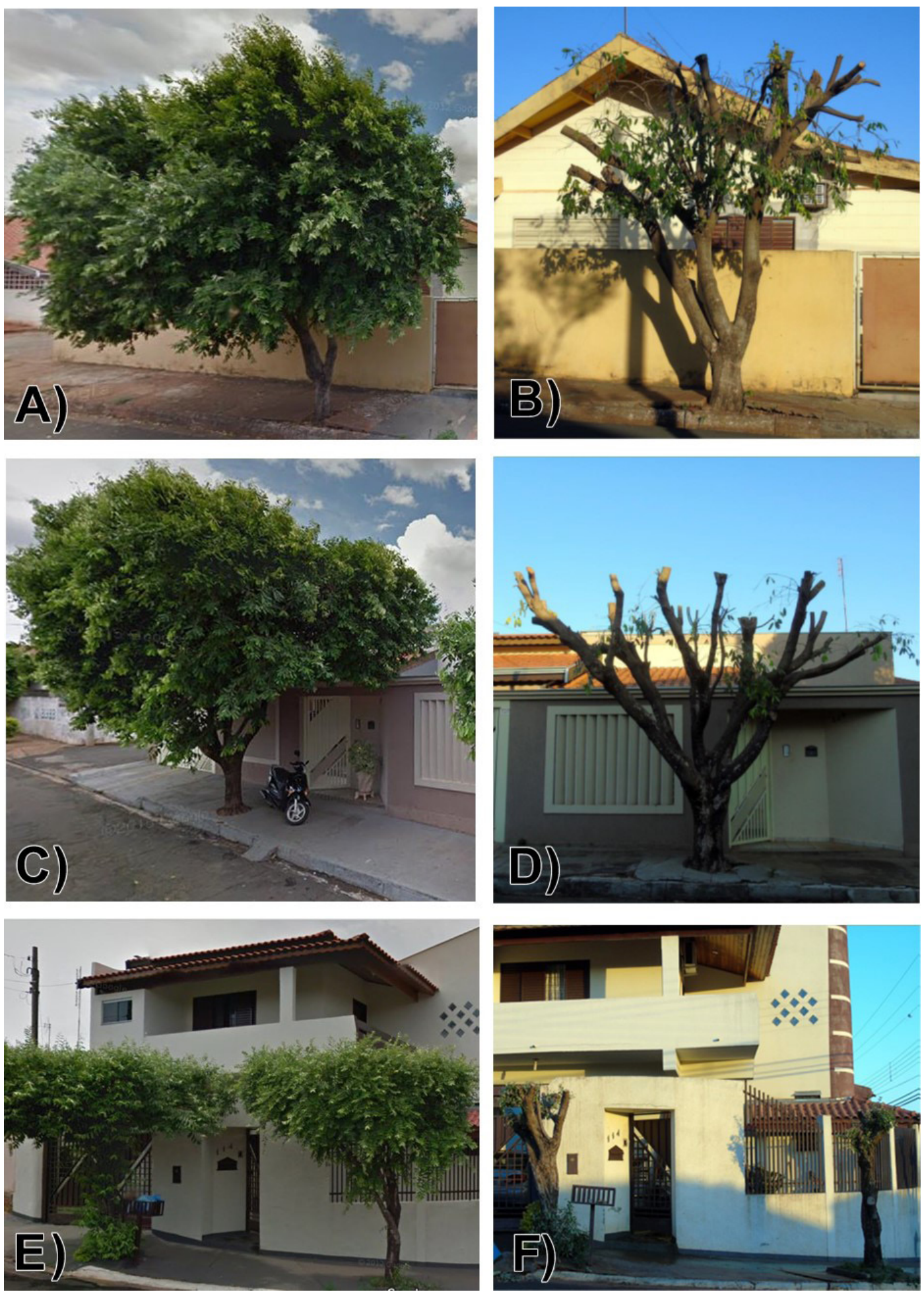

Fig. 4. Árvores de Oiti em Ilha Solteira - SP. (a, c, e) antes e (b, d, f) após sofrer poda drástica. Fonte: (a, c, e) Google Street

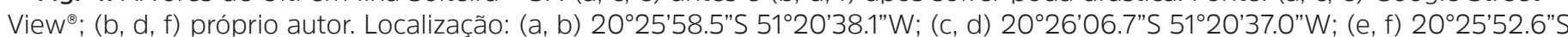
$51^{\circ} 20^{\prime} 01.7^{\prime \prime} \mathrm{W}$.

na parte exposta, prejudicando sensivelmente a árvore, além de interferir diretamente em aspectos fitossanitários (MARTINS; ANDRADE; ANGELIS, 2010).

De acordo com Milano e Dalcin (2000), a poda drástica também causa desequilíbro entre folhas e raízes, o que leva a reação compensatória no vegetal. Essa reação, manifesta-se através da quebra de dormência das gemas epicórmicas, gerando brotações que não tem ligação com o tronco principal e, com isso, esses novos "galhos" se tornam susceptíveis a quedas quando adultos, devido a ações intempéricas.

Além disso, deve-se considerar que implicações ecossistêmicas negativas são causadas quando se realizada este tipo de manejo na árvore. Em geral, a 
arborização urbana promove uma série de serviços ecossistêmicos, dentre os quais se destacam a amenização climática, o sequestro e estoque de carbono, a própria atenuação da poluição atmosférica e a manutenção da biodiversidade.

Nowak et al. (2018) observaram que as árvores urbanas de 86 cidades canadenses foram responsáveis pela remoção de 16.500 toneladas de poluição do ar no ano de 2010. Este serviço prestado predominantemente pela copa das árvores teve efeitos diretos na saúde humana da população avaliados em \$227,2 milhões de dólares canadenses. Socialmente, este serviço prestado evitou a morte de 30 pessoas e 22 mil incidências de problemas respiratórios agudo nas cidades.

No âmbito dos serviços ecossistêmicos, destacase que as árvores urbanas têm elevado potencial de umidificação da atmosfera pelo fenômeno da evapotranspiração. Alguns autores têm mostrado que as árvores urbanas podem reduzir a intensidade das ilhas de calor ao fornecer sombra e resfriamento por meio da perda de água da copa. As árvores urbanas são talvez a abordagem mais eficaz e menos dispendiosa para a mitigação e adaptação de ilhas de calor urbanas (NORTON et al., 2015; SOLECKI et al., 2005).

Capotorti et al. (2017) mostraram que o conjunto de árvores urbanas na cidade de Roma foram imprescindiveis para a manutenção da biodiversidade por meio do fluxo gênico de aves e artrópodes. Os autores fizeram um estudo biogeográfico e mostrarama relevância da vegetação nativa na manutenção de populações viáveis. Nesta perspectiva, espécies nativas e exóticas têm papeis funcionais semelhantes na promoção de serviços ecossistêmicos. Independentemente da origem biogeográfica das espécies, a manutenção de árvores viáveis é de fundamental importância para futuros cenários de mudanças climáticas e bemestar da população.

Uma função bastante relevante das árvores urbanas é o sequestro de carbono, dado que o aumento da concentração deste elemento na atmosfera tem sido amplamente debatido por países de todo o mundo. Em geral, as copas das árvores urbanas amenizam parte das emissões antropogênicas por meio de sequestro de $\mathrm{CO}_{2}$, o qual é fixado pelo fenômeno da fotossíntese. Com isso, entende-se que manter árvores urbanas sadias e com suas respectivas copas é uma forma alternativa de atenuar alguns impactos do modo de vida em cidades. Nowak et al. (2013) mostraram que árvores urbanas dos Estados Unidos tendem a representar $7,69 \mathrm{~kg} \mathrm{C} \mathrm{m}^{-2}$ com sequestro de carbono médio avaliado em $0,28 \mathrm{~kg} \mathrm{C} \mathrm{m}^{-2}$. Este valor foi monetariamente convertido pelos pesquisadores e isso representou um montante de US\$ 50,5 bilhões armazenados nos indivíduos arbóreos, com valor de sequestro anual orçado em US\$ 2 bilhões. Portanto, pensar na manutenção de árvores que sequestram carbono pelas suas copas é pensar monetariamente no planejamento das cidades.

Os dados do presente trabalho refletem a situação de algumas cidades brasileiras, onde a prática da poda de árvores nas ruas é executada de maneira empírica e sem a utilização de técnicas adequadas (LIMA, 2007). Para Periotto et al. (2019), a poda deve ser realizada por equipe técnica habilitada e em situações que se julguem necessárias, como interferência da copa com fiações, obstrução da sinalização viária, controle fitossanitário dentre outros, sempre preservando as condições vitais da árvore e mantendo os benefícios ambientais oferecidos por ela. Segundo a COELBA (2002), o planejamento adequado da arborização poderá contribuir para a melhoria da convivência no meio urbano, no entanto, requer o reconhecimento da realidade local, ou seja, dos padrões urbanísticos, culturais e biológicos predominantes.

\section{Conclusões}

O manejo inadequado da arborização urbana pela própria população pode trazer implicações que comprometam a vida do indivíduo arbóreo como um todo, além do comprometer também a prestação de serviços ecossistêmicos.

O comprometimento de funções ecossistêmicas é uma das principais perdas ocorridas pelo manejo inadequado de árvores urbanas. Para futuros cenários urbanos e climáticos, sugere-se que a arborização seja uma pauta prioritária na agenda e 
no planejamento ambiental estratégico.

O manejo de árvores urbanas exige critérios específicos, o qual não pode ser feito aleatoriamente pelo próprio munícipe. Para isso, serviços especializados de gestão ambiental devem ser solicitados em cada cidade brasileira. Destaca-se por fim, que a escolha correta das espécies a serem plantadas na arborização urbana é de extrema importância e deve ser realizada por profissionais qualificados e com relativa expertise no assunto.

Embora seja um ponto muito importante, tornase necessário ampliar pesquisas desta natureza para outras regiões urbanas, as quais provavelmente apresentam problemas semelhantes.

\section{Referências bibliográficas}

ASSOCIAÇÃO BRASILEIRA DE NORMAS TÉCNICAS. ABNT NBR 9050: Acessibilidade a edificações, mobiliário, espaços e equipamentos urbanos. Rio de Janeiro: ABNT, 2015.

ABREU, P. Ekonomista: Estas são as $\mathbf{5}$ plantas que causam mais alergia. 2018. Disponível: <https:// www.e-konomista.pt/plantas-que-causam-maisalergia/>. Acesso em: 19 set. 2019.

BARROS, E. F. S.; GUIHERME, F. A. G.; CARVALHO, R. S. Arborização urbana em quadras de diferentes padrões construtivos na cidade de jataí. Revista Árvore, v. 34, n. 2, p. 287-295, 2010.

BENNETT, J. H. \& HILL, A. C. Interactions of air pollutants with canopies of vegetation. In: MUDD, J.B. \& KOZLOWSKY, T.T. Response of plants to air pollution. New York:Academic Press, 1975. p. 273306.

BORTOLETO, S. Inventário quali-quantitativo da arborização viária da Estância de Águas de São Pedro. 2004. 99f. Dissertação (Mestrado em Agronomia) - Escola Superior de Agricultura "Luiz de Queiroz. Universidade de São Paulo, Piracicaba 2004

BRASIL. Lei $\mathbf{n}^{0} \mathbf{9 . 6 0 5}$ de 1998: Dispõe sobre as sanções penais e administrativas derivadas de lei de crimes ambietais, condutas e atividades lesivas ao meio ambiente (Lei de Crimes Ambientais). 1998.

CAPOTORTI, G. et al. Combining the conservation of biodiversity with the provision of ecosystem services in urban green infrastructure planning: Critical features arising from a case study in the metropolitan area of Rome. Sustainability, v. 9, n. 1, p. 10, 2017.

CARCERERI, V. H.; BIONDI, D.; BATISTA, A. C. Análise da cobertura arbórea das praças de Curitiba-PR. Revista da Sociedade Brasileira de Arborização Urbana, v. 11, n. 2, p. 12-26, 2016.

COELBA - Companhia de Eletricidade do estado da Bahia/Diretoria de Gestão de Ativos/Departamento de Planejamento dos Investimentos/Unidade Meio Ambiente. Guia de Arborização Urbana. Salvador: Venturie Gráfica e Editora, 2002.

COSTA, L. A. C.; HIGUCHI, N. Arborização de ruas de Manaus: avaliação qualitativa e quantitativa. Revista Árvore, v. 23, n. 2, p. 223-232, 1999.

DADOS CLIMÁTICOS - ILHA SOLTEIRA/SP. Canal CLIMA da UNESP Ilha Solteira - Área de Hidráulica e Irrigação. 2018. Disponível em: <http://clima.feis. unesp.br/recebe_formulario.php>. Acesso em: 19 set. 2019.

ESCOBEDO, F.; SEITZ, J. The costs of managing an urban forest. University of Florida:EDIS, 2009. 4p. Disponível em: < https://edis.ifas.ufl.edu/pdffiles/ FR/FR27900.pdf>. Acesso em: 10 out. 2012.

FERREIRA, F. A.; GASPAROTTO, L.; LIMA, M. I. P. M. Uma ferrugem, causada por Phakopsora tomentosae em oiti, em Manaus. Fitopatologia Brasileira, Brasília, v. 26, n. 2, p. $206-208,2001$.

GAUCHAZH. Comportamento: Conheça as plantas que podem desencadear processos alérgicos. 2011. Disponível em: <https://gauchazh.clicrbs. com.br/comportamento/noticia/2011/03/conheca- 
as-plantas-que-podem-desencadear-processosalergicos-3228183.html>. Acesso em: 19 set. 2019.

GOOGLE STREET VIEW. Imagens em $360^{\circ}$ do mapa de Ilha Solteira. 2012. Disponível em: <https:// www.google.com.br/maps/place/llha+Solteira++SP/@-20.4899271,-51.3591621,11z/data=!3m1!4b 1!4m5!3m4!1s0x9499f8719482b45b:0x2763c44f dc87bc75!8m2!3d-20.4323064!4d-51.3487221>. Acesso em: 01 de setembro de 2016.

IBGE. Instituto Brasileiro de Geografia e Estatística. Dados Ilha Solteira/SP. Disponível em: <http://cod. ibge.gov.br/3FG> acesso em: 08 de Maio de 2017.

ILHA SOLTEIRA. Lei Municipal n 441 de 1997. Disciplina o plantio de árvores no município de Ilha Solteira, e dá outras providências. 1997.

ILHA SOLTEIRA. Novos locais e dias de coleta do lixo reciclável. Disponível em: <http://www. ilhasolteira.sp.gov.br/index.php?option=com content\&view $=$ article $\& i d=24 \&$ ltemid $=20$ > . Acesso em: 02 de fevereiro de 2018.

LIMA, B. L. et al. Descrição das árvores encontradas nas ruas de Bandeirantes-PR. Revista Brasileira de Biociências, v. 5, p. 609-611, 2007.

LORENZI, $H$. Árvores brasileiras: manual de identificação e cultivo de plantas arbóreas nativas do Brasil. $5^{a}$ ed. Nova Odessa: Editora Plantarum, 2008. 384p.

MAREK, C. F. Os Impactos da arborização viária sobre a rede de distribuição de energia elétrica: estudo de caso da Zona 7 de Maringá/PR. 2008. 89p. Dissertação (Mestrado em Engenharia Urbana) - Universidade Estadual de Maringá. Maringá, 2008.

MARTINS, L. F. V.; ANDRADE, H. H. B.; ANGELIS, B. L. D. Relação entre podas e aspectos fitossanitários em árvores urbanas na cidade de Luiziana, Paraná. REVSBAU, Piracicaba - SP, v. 5, n. 4, p. 141-155, 2010.

MASCARÓ, L. R.; MASCARÓ, J. L. Vegetação Urbana.
Porto Alegre: UFRGS, 2002. 242p.

MENDONÇA; M. F.; FERREIRA, M. L. O uso do solo próximo à reservatórios de abastecimento hídricos e suas implicações com a prestação por serviços ambientais: uma abordagem baseada em valorização monetária. In: ZABOTTO, A. Estudos sobre impactos ambientais: Uma abordagem contemporânea. Botucatu: FEPAF, 2019. p. 25-57.

MILANO, M.; DALCIN, E. Arborização de vias públicas. Rio de Janeiro: Light, 2000. 206p.

NORTON, B.A. et al. Planning for cooler cities: A framework to prioritise green infrastructure to mitigate high temperatures in urban landscapes. Landscape and Urban Planning, v. 134, p. 127-138, 2015.

NOWAK, D. J. et al. Air pollution removal by urban forests in Canada and its effect on air quality and human health. Urban Forestry \& Urban Greening, v. 29, p. $40-48,2018$

OLIVEIRA, N. B. et al. Avaliação do estado nutricional de três gramados ornamentais em Ilha Solteira-SP: um estudo de caso. Revista LABVERDE, v. 9, n. 1, p. 96-119, 2018.

PERIOTTO, F. et al. Arborização urbana: características, funções e manejo. In: Estudos sobre impactos ambientais: Uma abordagem contemporânea, Editora FEPAF, Botucatu, 293p, 2019.

PINHEIRO, R. R Condição da arborização da avenida Brasil, no município de Ilha Solteira-SP. In: anais do $6^{\circ}$ Congresso de Extensão Universitária, 2011, Águas de Lindóia, SP. Anais... $6^{\circ}$ Congresso de Extensão Universitária, 2011.

PINTEREST. Keep gutters leaf-free. Disponível em: <https://br.pinterest.com/ pin/517843657138475435/>. Acesso em: 19 set. 2019.

POSSAMAI, L. Aspectos qualitativos da arborização 
de ruas do bairro Santa Catarina, São Miguel do Iguaçu, PR. Cultura Agronômica, v. 27, n. 1, p. 141147, 2018.

PREFEITURA MUNICIPAL DE SÃO PAULO. Manual técnico de arborização urbana. Prefeitura de São Paulo. Secretário Municipal do Verde e do Meio Ambiente, $3^{a}$ edição, 122 p. 2015.

REDE CIDADE DIGITAL. Mapa das cidades digitais São Paulo. Disponível em: <http://redecidadedigital. com.br/mapa_sp.php>. Acesso em: 02 de fevereiro de 2018.

SANTOS, P. L. F.; BARCELOS, J. P. Q.; CASTILHO, R. M. $M$. Diferentes substratos no desenvolvimento de um gramado ornamental para uso em telhados verdes. Periódico Técnico e Científico Cidades Verdes, v. 04, n. 10, p. 81-94, 2016.

SANTOS, P. L. F.; CASTILHO, R. M. M. Floriferous herbaceous and substrates for use on extensive green roofs. Ornamental Horticulture, v. 24, n. 3, p. 261-268, 2018.

SEITZ, R. A. A Poda de Árvores Urbanas. Manual sobre Poda em Espécies Arbóreas Florestais e de Arborização Urbana. FUPEF - Fundação de Pesquisas Florestais do Paraná/Curitiba, 1996. 27 p.

SILVA FILHO, D. F. Cadastramento informatizado, sistematização e análise da arborização das vias públicas da área urbana do município de Jaboticabal, SP. 81f. Dissertação (Mestrado em Geografia). Universidade Estadual Paulista, Jaboticabal, 2002.

SILVA FILHO, D. F. et al. Banco de dados relacional para cadastro, avaliação e manejo da arborização urbana. Revista Árvore. Viçosa, v. 26, n. 5, p. 629642, 2002.

SILVA, E. M. et al. Estudo da arborização urbana do Bairro Mansur na cidade de Uberlândia-MG. Caminhos de Geografia, v. 3, n. 5, p. 73-83, 2002. effect in urban New Jersey. Global Environmental Change Part B: Environmental Hazards, v. 6, n. 11, p. 39-49, 2005. 